\title{
A DANZA DE EL TIGRE E 0 AUTO DO BOI CONEXÕES ENTRE SISTEMAS DANCÍSTICOS, PERFORMANCES E DRAMAS SOCIAIS NO CONTEXTO DO DIÁLOGO INTERCULTURAL LATINO-AMERICANO
}

Walace de Deus Barbosa (UFF)

Estudo etnográfico de um gênero de danças tradicionais executado por etnias indígenas de um trecho da costa oeste mexicana ${ }^{1}$ e segmentos da população mestiça, cujo roteiro encena a atualização de um drama social envolvendo o processo colonial, a atividade agropecuária e o diálogo intercultural entre as figuras (genéricas) do índio, do fazendeiro e do camponês. Esta etnografia pretende explorar alguns paralelos da danza del tigre com folguedos populares brasileiros, particularmente o bumba meu boi, apontando ainda para a realidade de alguns grupos indígenas no Nordeste do Brasil, cujo processo de afirmação identitária em diálogo com o Estado nacional produziu gêneros performáticos e proporcionou a difusão de sistemas dancistas (sendo o toré o mais conhecido), acionados nos diálogos com a sociedade nacional.

ANTROPOLOGIA DA DANÇA, ETNOLOGIA INDÍGENA, PATRIMÔNIO IMATERIAL, CULTURAS POPULARES.

BARBOSA, Walace de Deus. A danza de el tigre e o auto do boi: conexões entre sistemas dancísticos, performances e dramas sociais no contexto do diálogo intercultural latino-americano. Textos escolhidos de cultura e arte populares, Rio de Janeiro, v.9, n.2, p. 193-205, nov. 2012. 


\section{THE DANZA DE EL TIGRE AND THE AUTO DO BOI}

BETWEEN DANCING SYSTEMS, DRAMAS AND SOCIAL PERFORMANCES IN THE CONTEXT OF LATIN AMERICAN INTERCULTURAL DIALOGUE.

Wallace De Deus Barbosa (UFF)

This is an ethnographic study of a genre of traditional dances performed by indigenous groups from a stretch of land in the Mexican west coast and segments of the Mexican mestizo population, whose script performs the updating of a social drama involving the colonial process, agricultural activities and intercultural dialogue between the (generic) figures of the indian, the farmer, and the peasant. This ethnography aims at exploring some parallels between the danza del tigre and Brazilian popular genres, particularly bumba meu boi, with emphasis on the reality of some indigenous groups in northeastern Brazil, inside which a process of identity affirmation in direct dialogue with the national State has produced performance genres as well as provided the spreading of dancing systems (toré being the best known), triggered by dialogues with the national society.

\section{ANTHROPOLOGY OF DANCE, INDIAN ETHNOLOGY, INTANGIBLE HERITAGE, POPULAR CULTURES.}

BARBOSA, Walace de Deus. A danza de el tigre e o auto do boi: conexões entre sistemas dancísticos, performances e dramas sociais no contexto do diálogo intercultural latino-americano. Textos escolhidos de cultura e arte populares, Rio de Janeiro, v.9, n.2, p. 193-205, nov. 2012. 
Al consumarse la muerte del felino se reafirma la dominación del español

\section{INTRODUÇÃO E JUSTIFICATIVA}

No Brasil não temos ainda estabelecido um campo de estudos que, no México, já foi, há muito, consolidado pela rubrica antropologia de la danza. Esse campo abrange os estudos das danças tradicionais e das performances de cunho identitário, sobretudo aquelas realizadas por grupos indígenas em contextos de diálogo com o Estado nacional. Em 1999, atuamos como auxiliar de pesquisa ${ }^{3}$ junto com o professor doutor Carlo Bonfiglioli, da Universidad Nacional Autónoma de México - Unam, em um povoado do estado mexicano de Guerrero (Tlacoachistlahuaca) registrando em mídia audiovisual dois sistemas dancistas encenados pelos índios da etnia amuzgo (língua isolada) com o concurso de parte da comunidade mestiza e não índia daquele pequeno pueblo. O objeto de atenção principal do professor Bonfiglioli, na ocasião, era a danza de la conquista, espécie de narrativa teatral nativa da chegada de Cortez ao México, encenada nas comemorações que antecedem o dia de Nossa Senhora da Conceição, no início de dezembro. Em época de muitos festejos de final de ano, ocorriam também outras manifestações dancistas encenadas por índios e mestizos, como a chamada danza del tigre, que também nos proporcionou a oportunidade de realizar alguns registros esparsos. De lá para cá, mantivemos contatos intermitentes com o doutor Bonfiglioli, aguardando ocasião oportuna de explorar os desdobramentos daquela primeira incursão para estreitar nossas vinculações acadêmicas e de pesquisa.

Em 2004, na 24a Reunião Brasileira de Antropologia - ABA, na cidade do Recife (PE), juntamente com a professora doutora Regina Pólo Müller (Unicamp), coordenamos um Fórum de Pesquisa intitulado Artes étnicas e performance, cuja justificativa residia na constatação de que, no cenário da antropologia brasileira contemporânea (sobretudo naquelas vertentes que abrangem o amplo campo do que se convencionou chamar de antropologia da arte) prevaleceu, desde os anos 70, uma tendência de estudos etnológicos cujas discussões se voltavam predominantemente para a análise das representações visuais de grupos em relativo grau de isolamento (em sua maior parte, xinguanos ou amazônicos), associando-as a cosmologias específicas.

No bojo dessas discussões encontravam-se também grandes investimentos reflexivos e de indexação de itens da chamada 'cultura material' ameríndia, aliados a preocupações com processos de mudança cultural, promovidos particularmente pela introdução de 'materiais heteróclitos' (fios de náilon, corantes artificiais, tecidos e materiais sintéticos) na produção 
artesanal indígena (RIBEIRO, 1988). Essas abordagens estavam fortemente influenciadas pelos chamados estudos dos processos aculturativos por um lado e pela antropologia estrutural por outro. A partir das décadas de 1980 e 1990, a atenção dos especialistas em artes étnicas amplia-se de modo a se voltar para as estratégias de afirmação identitária, etnicidade e outros processos de afirmação de culturas locais (OLIVEIRA FILHO, 1999), quando manifestações artísticas em sociedades indígenas voltam a despertar interesse, renovado pelos estudos da performance que constituem, em nossa atualidade antropológica, importante campo de reflexão (MüLLER, 1997). Nesse contexto, ampliam-se os horizontes das etnicidades indígenas tradicionais e inserem-se como objetos de análise as práticas culturais populares, os rituais e os folguedos, até então arrolados como cultura popular ou folclore. Hoje, no entanto, o tipo de abordagem que se apresenta difere significativamente das perspectivas salvacionistas dos chamados estudos folclóricos (VILHENA, 1997).

No contexto da antropologia que é feita no Brasil, seja a partir das teorias da performance (MüLLER, 1997) ou através da perspectiva teórica que aborda a arte como "fonte e alvo de agenciamento social", como em Alfred Gell (1998), ampliam-se os próprios horizontes das abordagens vinculadas a uma antropologia da arte que tem como objeto de investigação as performances e danças de povos tradicionais. Nessa perspectiva, é preferível não se definir a priori o que pode ser considerado arte ou artístico, uma vez que é no plano contextual e/ou relacional que tal perspectiva se apresenta, tanto para os modos de ação que envolvem as performances quanto para os que são mediados por artefatos. Neste último caso, algumas das teses de Alfred Gell (1998) têm sido o ponto de partida para atualizações teórico-metodológicas em discussões que circundam esse campo. ${ }^{4}$

Na pesquisa a que nos lançamos durante estágio pós-doutoral (em 2007 e 2008) no Instituto de Investigaciones Antropológicas da Unam, pretendíamos dar continuidade a uma reflexão já anunciada desde nossa tese de doutorado (BARBOSA, 2001, 2003 e 2005), quando aludimos à relação entre determinadas práticas performáticas (encenadas por povos indígenas de Pernambuco no processo de busca do reconhecimento oficial), em especial o toré, e o complexo dancista indígena existente em alguns estados mexicanos - circunscritos em universos etnográficos muito bem definidos (JÁUREGUI; BONFIGLIOLI, 1996) genericamente chamado las danzas de conquista, e notamos que:

os índios encenam a saga da conquista do México-Tenochtitlan por Cortez, reinterpretada dramaticamente a partir de uma série de eventos históricos. Tivemos a oportunidade de acompanhar a 
execução de extensos trechos de uma dessas danças pelos índios amusgo do povoado Tlachoachistlahuaca na costa oeste mexicana, em dezembro de 1999, a convite do antropólogo Carlo Bonfiglioli da Unam (BARBOSA, 2001).

Trabalhando com acervos de cultura material indígena, entre 1988 e 1995 sob a supervisão da professora Maria Heloísa Fénelon Costa e depois do professor João Pacheco de Oliveira, responsáveis sucessivos pelo Setor de Etnologia, do Departamento de Antropologia do Museu Nacional/UFRJ, colaboramos na sistematização do acervo de itens de cultura material ameríndia do Setor e iniciamos pesquisa entre os índios Kambiwá de Pernambuco, que redundou na dissertação (BARBOSA, 1991), no âmbito do mestrado em Artes Visuais da Escola de Belas Artes/UFRJ. Posteriormente, no doutorado, prosseguimos a etnografia entre os kambiwá, incluindo os índios pipipã, ao refletir sobre o processo de sua "etnogênese" e a concomitante constituição de um repertório de práticas rituais e performances, a partir daí tomadas como objeto de nosso campo de investigação (BARBOSA, 2001, 2003).

$\mathrm{Na}$ atual etapa de nossos investimentos de pesquisa, adentramos gradativamente o campo das performances de cunho identitário, expressas tanto no movimento indígena como em campos diversos, como na 'capoeira', por exemplo, cuja modalidade 'angola' enseja questões de ordem reflexiva que permitem o estabelecimento de algumas conexões parciais com a realidade das danças e performances entre povos indígenas em processos de afirmação étnica e mudança cultural (BARBOSA, 2005). Nesse entendimento e perspectiva, como pesquisador associado ao Laced (Museu Nacional/UFRJ), tive a chance de coordenar entre 2005 e 2007 (ainda antes da partida para o México) o "Inventário e registro para a salvaguarda da capoeira como patrimônio imaterial do Brasil", através do DPI/Iphan, Laced/MN-UFRJ e Centro Nacional de Folclore e Cultura Popular - CNFCP, junto com o professor doutor Maurício Barros de Castro. Por intermédio do professor doutor Antonio Carlos de Souza Lima, coordenador do Laced, ${ }^{5}$ na ocasião, iniciamos os trabalhos de prospecção desse bem cultural, tanto na perspectiva do saber tradicional do mestre de capoeira como no reconhecimento da roda de capoeira como forma de expressão. ${ }^{6}$

\section{AS LIMITAÇÕES DO MÉTODO COMPARATIVO EM ANTROPOLOGIA DA DANÇA}

A investigação histórica deve ser o teste crítico demandado pela ciência antes que ela admita os fatos como evidências.

A comparabilidade do material coletado precisa ser testada por esse meio (BOAS, [1896] 2004). 
Quando comentamos com o supervisor acadêmico da pesquisa de pós-doutorado, o professor doutor Bonfiglioli, sobre a intenção de realizar um estudo comparativo - bem ao sabor da tradição antropológica - entre a danza del tigre e o bumba meu boi, motivados pela constatação de algumas semelhanças bastante superficiais entre as duas performances (o contexto da tradição agrária; a estrutura das relações de poder entre o camponês, o índio e o fazendeiro; e até mesmo os perfis sociais e nomes de alguns personagens de ambos os dramas: Catarina/Catalina; Velho Chico/Viejo, etc.) sua resposta em 'portunhol' foi bem-humorada e taxativa:

Nosso amigo, aquele francês de 98 anos, diz que todo estudio comparativo tiene dos riesgos: que el objeto sea demasiado cercano para encontrar diferencias, o demasiado lejano para las semejanzas. Tomara que o teu esteja no meio do camino! El tigre tiene a que ver con lo interétnico, con la satira a los mestizos, con el nahualismo.

A análise dos sistemas dancistas aqui anunciados, a saber, as variadas e circunscritas versões da danza del tigre, o bumba meu boi e o toré, promove o desenvolvimento de reflexões que poderão contribuir para o esboço de uma análise comparativa no campo das performances, danças e encenações tradicionais, mas também permitirá pensar as políticas públicas de patrimônio imaterial (patrimonio intangible, como é mais referido no contexto latinoamericano) no México e no Brasil em contextos semelhantes, sob alguns aspectos, no que diz respeito à realidade dos povos indígenas latinoamericanos. Não se tratava, entretanto, de estudo comparativo entendido no sentido estrito do termo, ainda que algumas conexões parciais fossem particularmente visíveis e apontassem para o lugar estratégico dos rituais e danças na atualização das estruturas de poder subjacentes ao diálogo cultural, no bojo no Estado nacional.

No caso dos índios mexicanos (da etnia amuzgo) constatamos que o contexto de realização da danza é o da mestiçagem, sempre no âmbito do diálogo com a sociedade nacional mexicana. No caso brasileiro, a realização do bumba meu boi traz a figura do índio, representada no plano simbólico, ensejando o diálogo entre os personagens que representam as forças nativas, o colonizador e o mestizo. Já os torés dos povos indígenas de Pernambuco, por exemplo, estão conectados com os movimentos mais gerais de afirmação étnica no Nordeste brasileiro, no contexto dos chamados "índios misturados" (OLIVEIRA, 1999), mas também inseridos em situação de diálogo com a sociedade nacional. 


\section{DANZA DE EL TIGRE}

A chamada danza del tigre - performance intercultural de matriz indígena-mestiça encontradiça em diversos povoados do estado mexicano de Guerrero - integra um jogo dramático que pode ser entendido como metáfora da colonização espanhola e do submetimento dos povos indígenas ao jugo colonial no México. Isso se reforça porque o tecuani, ${ }^{7}$ forma vernacular de designação do tigre, representa os poderes selvagens dos conquistados, que são capazes de ameaçar uma das principais atividades econômicas dos conquistadores, a pecuária. Em uma de suas versões, a danza, que pode durar até três dias ou mais, ao consumar a morte do tigre (jaguar, onça) simbolicamente reafirma e atualiza o jugo colonial espanhol, segundo algumas análises (JÁUREGUI; BONFIGLIOLI, 1996).

O tigre é animal que tem inspirado inúmeros bailes e danzas, em diversas regiões mexicanas. Uma das versões mais conhecidas da danza del tigre ocorre em San Juan Colorado, município do Distrito de Jamiltepec, com aproximadamente sete mil habitantes. A população local se dedica principalmente às atividades agropecuárias e ao comércio. Nesse município, mais de quatro mil indivíduos maiores de cinco anos falam a língua indígena, o mixteco, cuja grande vitalidade social se deve ao fato de ser usada na vida diária e cerimonial.

A versão mais genérica da danza encena a história de ricos fazendeiros de uma dada região que são sistematicamente atormentados por uma espécie de "tigre mágico" ${ }^{18}$ que ataca seu gado. Um dos fazendeiros vitimados pelo jaguar tenta comprar um cachorro caçador de um homem do povo que se recusa vender o animal (conhecido pela eficácia na caça), alegando ser de propriedade de sua esposa, doña Catalina. O cachorro havia sido indicado por sua destreza em acuar tigres, mas não atuava bem longe de sua dona ("sólo con ella sabe cazar"). Devido a isso o fazendeiro resolve contratar o casal para, junto com seu cachorro, ajudá-lo a caçar o tigre. A busca se desenrola até o momento em que o cachorro encontra o jaguar (tigre), quando começa a caçada propriamente dita: o fazendeiro dispara contra o tigre com sua espingarda, mas não o atinge. Doña Catalina indica o lugar onde está o felino, e o cachorro começa a ladrar ao redor da árvore em que se esconde el tigre. Essa, ao menos, foi uma primeira versão da danza que presenciei em Tlachoachistlauaca, estado de Guerrero, em 1999.

Doze dançantes acompanham os caçadores bailando ao redor do lugar em que se encontra el tigre. Os projéteis contra eles disparados não Ihe causam 
nenhum dano, pois se trata de um “tigre mágico". Desse modo, doña Catalina sugere a seu esposo que atire alho contra o animal para que se quebre o feitiço. Atingido, finalmente o fazendeiro mata el tigre, retira-lhe a pele e atira-a em um barranco. Antes disso, porém, os dançantes que interpretam o tigre e o cachorro realizam passos espetaculares e acrobacias simulando a peleja. O clímax da festa/dança se dá com a morte de el tigre e a afirmação simbólica da nação mexicana.

\section{O AUTO DO BOI}

Tradicionalmente realizado no estado do Maranhão e alhures durante o período das festas juninas, mas também eventualmente no Natal ou carnaval, o folguedo do bumba meu boi encena o rapto, morte e ressurreição de um boi que, de certo modo, se associa ao ciclo agrário. Em linhas gerais, o auto do boi, como também é chamado, apresenta-se na forma de um drama de morte e ressurreição de um "boi especial". A cena se desenrola a partir do drama pessoal vivido por um escravo ou descendente de escravos que, premido por um insaciável desejo de sua esposa grávida, é levado a experimentar, tal qual o boi, situação liminar, entre a vida e a morte (CARVALHO, 2005).

A trama se passa numa fazenda em que existe certo Boi Precioso, especialmente querido por seu dono, o fazendeiro, a quem seus empregados dispensam os maiores cuidados. Certo dia, um homem de confiança do patrão, o chamado Pai Francisco, para atender aos incessantes apelos de sua esposa, Mãe Catirina (ou simplesmente Catarina), decide roubar o boi, matá-lo e arrancar-lhe a língua, dando à esposa a iguaria com a qual ela satisfaz seus desejos de grávida.

O crime é descoberto e Chico (ou Pai Francisco) é perseguido pelos homens do fazendeiro, auxiliados pelos índios, exímios conhecedores da terra. O personagem do Pai Francisco acaba sendo capturado, submetido a terríveis castigos físicos e, para não pagar com sua a vida, é levado a trazer de volta o boi para o convívio da fazenda. Para essa tarefa impossível, recebe a ajuda de pretensos sábios doutores, até que, finalmente, depois de apelar para muitos artifícios, recebe o auxílio de um pajé (índio) que consegue fazer com que o animal ressuscite, para alegria geral dos convivas, que se põem a comemorar em torno do animal, com muita música e dança. O boi, figura central do auto, geralmente é montado com armação de cipó coberta de chita, grande o bastante para que um homem a vista. A cabeça pode ser feita de papelão ou com a própria caveira do animal. 
Outros personagens podem entrar na história para dançar, dependendo do tipo de boi: Bastião, Arlequim, Pastorinha, Turtuqué, o engenheiro, o padre, o médico, o diabo, etc., todos quase sempre interpretados por homens, que se travestem para compor os personagens femininos. Do ponto de vista teatral, o folguedo deriva das tradições espanhola e portuguesa, tanto no que diz respeito ao desfile como à representação propriamente dita; tradição de se encenarem peças religiosas de inspiração erudita, mas destinadas ao povo, para comemorar festas católicas nascidas na luta da Igreja contra o paganismo. Esse costume foi retomado no Brasil pelos jesuítas em sua obra de evangelização dos indígenas, negros e dos próprios portugueses aventureiros e conquistadores, por meio da encenação de breves peças (CARVALHO, 2005).

Como dança dramática, o bumba meu boi adquire ao longo do tempo algumas características dos autos medievais, o que lhe dá o caráter de veículo de comunicação. Simples, emocional, direto, em linguagem oral e narrativa clara, com ampla identificação por parte do público, toma semelhanças com a comédia satírica ou tragicomédia pela estrutura dramática de seus personagens alegóricos, por incidentes cômicos e contextuais, gravidade dos conflitos e desenlace quase sempre alegre, que funciona como processo catártico. Em suas muitas versões, esse roteiro básico estaria presente, sob diversas rubricas, em todo o extenso ciclo narrativo associado ao personagem do boi no Brasil, independentemente de se revestir ou não de forma dramatizada de expressão (CAVALCANTI, 2003).

\section{CONSIDERAÇÕES FINAIS: DIÁLOGO CULTURAL, DANÇAS, PERFORMANCES E JOGOS DRAMÁTICOS}

Em 1997, o bárbaro assassinato do índio pataxó hãhãhãe Galdino Jesus dos Santos, então com 44 anos, da aldeia Caramuru/Paraguaçu, no sul da Bahia, internacionalmente conhecido como Galdino Pataxó, fez com que a opinião pública conhecesse um meio de expressão muito comum entre os povos indígenas do Nordeste, empreendido, naquela ocasião, na forma de um protesto indignado que a imprensa chamou de toré. Essa é, na verdade, uma das práticas mais difundidas no contexto desses povos; modalidade ritual que, descrita como uma espécie de iniciação, envolve, em escalas aproximadas, elementos religiosos, políticos ou simplesmente lúdicos, apresentados de forma claramente performática. Muitas vezes utilizado como uma espécie de cartão de visitas dos índios, quando da presença de eventuais visitantes desejosos de conhecer seus costumes. Em outra ocasião, sugerimos que esse processo de transmissão cultural poderia ser denominado tráfico simbólico (BARBOSA, 
1999). Fato é que a performance do toré surge a partir do contexto de diálogo - ou tentativa de diálogo - dos povos indígenas com a sociedade nacional, particularmente entre os povos do Nordeste brasileiro. A mesma ideia de tráfico simbólico talvez nos permita pensar nos processos de difusão de expressões tradicionais e contemporâneas, como danças, performances e ritos os mais variados. A difusão do auto do boi, chegando a seu extremo moderno com o Festival Folclórico de Parintins (VALENTIN, 2005), desde as origens de sua reprodução nas mais variadas perspectivas, de igual modo, nos permite pensar nos espectros de propagação não só das ideias e representações, mas também dos gestos, dos passos e das pisadas, como sugere a antropóloga Yvonne Daniel (2005), da Universidade de Illinois (EUA), que reflete sobre a diáspora africana a partir do viés da corporeidade, do gesto e da dança, refletidos e processados diferentemente (com distintas ênfase no corpo) no vodu haitiano, na santería cubana e no candomblé da Bahia.

Durante a estada mexicana, percorremos variadas versões da danza de el tigre ou de tecuanis que diferiam em vários aspectos daquela primeira versão, de 1999. Em Acatlán de Osório, estado de Puebla, observamos a dança dos tecuanes convertida em expressão popular local, municipal, integrando grupos de migrantes que se deslocaram para o Distrito Federal em busca de melhores possibilidades de trabalho. Essas famílias se encontram anualmente no final do mês de outubro (24), dia de san Rafael Arcángel, padroeiro da cidade, em grupo de tecuanes e tlacoloreros (fazendeiros) que encenam uma das versões da saga que envolve el tigre associado à matriz indígena, e os fazendeiros ou pequenos proprietários rurais associados simbolicamente (como a atividade pecuária) ao domínio espanhol e, posteriormente, à constituição do moderno Estado mexicano. Em San Luiz de Acatlán, estado de Guerrero, ocorre a pelea de tecuanes no dia da Santa Cruz, 3 de maio, evento que congrega mais de uma dezena de diferentes danças indígenas e a famosa disputa entre os homens trajados de tigre, em um ritual de luta corporal, semelhante ao boxe, em que os protagonistas desfecham e recebem violentos socos munidos de luvas e máscaras de madeira, inspirados na figura do jaguar, referente de el tigre e/ou tecuane. Homens e crianças trajados de onça se embatem em rito propiciatório de petição de chuva, sempre no início do ciclo agrícola. Ocorre que tais versões da danças de tecuanes constituem tão somente variações em torno desse grande tema (a saber, da expansão da frente econômica agrária e o domínio colonial) que se expressa também em outras danças como el toro de petate e outras, genericamente arroladas na rubrica danzas de hacienda. Ao final de estada de um ano no México, com as questões acima esboçadas e 
após prospecções que abarcaram entre outros temas, o día de muertos, festas religiosas e o carnaval, ${ }^{9}$ a miríade das expressões dancistas e performances, retornamos às palavras do doutor Bonfiglioli e pensamos que talvez ele tivesse, desde o início, toda a razão quando de sua citação.

\section{REFERÊNCIAS BIBLIOGRÁFICAS}

BARBOSA, Wallace de Deus. Os índios kambiwá de Pernambuco: arte e identidade étnica. Dissertação de mestrado. Rio de Janeiro, Universidade Federal do Rio de Janeiro, Escola de Belas Artes, 1991.

$\mathrm{O}$ artesanato indígena e os 'novos' índios do Nordeste". Cidadania: Revista do Patrimônio Histórico e Artístico Nacional, n. 28, v., 1999, p. 198214.

. 'Um embate de culturas': análise de processos políticos e estratégias socioculturais na construção das identidades kambiwá e pipipã. Tese (doutorado em antropologia). Rio de Janeiro: PPGAS/MN/UFRJ, 2001.

. Pedra do encanto: dilemas culturais e disputas políticas entre os Kambiwá e os Pipipã. Rio de Janeiro: Editora Contracapa, 2003.

. O toré (e o praia) entre os Kambiwá e os Pipipã: performances, improvisações e disputas culturais. In GRÜNEWALD, R. de A. (Org.). Toré. Regime encantado do índio do Nordeste. Recife: Fundaj/Massangana, 2005.

BOAS, Franz. Antropologia Cultural. Rio de Janeiro: Jorge Zahar, 2004.

CARVALHO, Luciana Gonçalves de. A 'graça de contar': narrativas de um Pai Francisco no bumba meu boi do Maranhão. Tese (doutorado em ciências humanas). Rio de Janeiro: UFRJ, IFCS, 2005.

CAVALCANTI, Maria Laura V. de Castro. Cultura popular e sensibilidade romântica: as Danças Dramáticas de Mário de Andrade (ou por que Mário de Andrade viu no bumba não só "a mais exemplar" como também "a mais estranha" das danças dramáticas). Rio de Janeiro: XXVI Encontro Anual da Anpocs, 2003.

DANIEL, Yvonne. Dancing Wisdom. Embodied knowledge in Haitian Vodou, Cuban Yoruba, and Bahian Candomblé. Chicago: University of Illinois Press, 2005.

GELL, Alfred. Art and agency. An anthropological theory. Oxford: Oxford University Press, 1998.

JÁUREGUI, Jesus; BONFIGLIOLI, Carlo (orgs.). Las danzas de conquista, vol. 1: México contemporáneo. Ciudad de México: Fondo de Cultura Económica, 1996.

MÜLLER, Regina Pólo. Ritual e performance artística contemporânea. In OLIVEIRA FILHO João Pacheco de. Situação colonial, territorialização e fluxos culturais: elementos para uma etnologia dos "índios misturados". Conferência para o 
Concurso de Professor Titular do Departamento de Antropologia - Setor de Etnologia da Universidade Federal do Rio de Janeiro, 1997.

OLIVEIRA FILHO, João Pacheco de (org.). A viagem da volta: etnicidade, política e reelaboração cultural no Nordeste indígena. Contracapa Livraria, 1999.

RIBEIRO, Berta G. Dicionário do Artesanato Indígena. Belo Horizonte/São Paulo: Itatiaia/Edusp, 1988.

VALENTIN, Andreas. Contrários. A celebração da rivalidade dos bois-bumbás de Parintins. Manaus: Ed. Valer, 2005.

VILHENA, Luis Rodolfo da Paixão. Projeto e missão: o movimento folclórico brasileiro (1947-1964). Rio de Janeiro: FGV/Funarte, 1997.

\section{NOTAS}

1 Trata-se precisamente da região conhecida como Costa Chica, onde se localizam as comunidades amuzgas de Tlacoachistlahuaca, Xochistlahuaca y Cozoyoapán, no Estado de Guerrero.

2 Citação retirada de http://www.mexicodesconocido.com.mx. Acesso, 28.4.2007.

3 Vinculado como docente e pesquisador ao Departamento de Arte da Universidade Federal Fluminense - UFF e como doutorando do Programa DE Pósgraduação em Antropologia (PPGAS) do Museu Nacional/UFRJ. Os resultados dessa incursão estão relatados na tese de doutorado (BARBOSA, 2001), publicada em 2003 com o título Pedra do Encanto: dilemas culturais e disputas políticas entre os Kambiwá e os Pipipã.

4 A esse respeito, conferir também os Anais da V Reunião de Antropologia do Mercosul, 2002-2003, particularmente o Grupo de Trabalho sob a coordenação de Maria Elizabeth Lucas (PPGAS/PPGMUS/UFRGS) e de Deise Lucy Oliveira Montardo (Musa/Museu/UFSC).

5 Laboratório de Pesquisa em Etnicidade, Cultura e Desenvolvimento, vinculado ao Museu Nacional/UFRJ. http://www.laced.mn.ufrj.br

6 O saber tradicional do mestre de capoeira e a roda de capoeira como forma de expressão foram inscritos, em julho de 2008, respectivamente nos livros dos Saberes e das Formas de Expressão do Patrimônio Cultural brasileiro através da Diretoria de Patrimônio Imaterial do Iphan, a partir do dossiê produzido naquela ocasião (no prelo).

7 A palavra tecuani tem origem no náhuatl e significa, em espanhol, "algo que come".

$8 \mathrm{Na}$ verdade, não se trata de um tigre, mas de uma onça ou jaguar (Panthera onça, Lin.). 
9 A esse respeito, conferir Barbosa, Wallace de Deus. "El brinco de los chinelos": breves reflexões sobre o carnaval em Tepoztlán, México. Cadernos do Leme (UFCG), 2010. Disponível em http://www.ufcg.edu.br/ leme/pdf/Cadernos_ leme2pdf/LEME2_1_\%20Barbosa.pdf

Wallace de Deus Barbosa é professor adjunto do Departamento de Arte da Universidade Federal Fluminense e membro efetivo da Associação Brasileira de Antropologia - ABA. Como pesquisador associado ao Laced (Museu Nacional/ UFRJ) coordena o Inventário e registro para a salvaguarda da capoeira como patrimônio imaterial do Brasil, através do DPI/Iphan, Laced/MN-UFRJ e Centro Nacional de Folclore e Cultura Popular - CNFCP. 
